\title{
THE RELATIONSHIP BETWEEN FEED AND QUANTITY AND KIND OF WOOL PRODUCED
}

A. E. HENDERSON, Senior Lecturer and Head of Wool

Department, Canterbury Agricultural College, Christchurch

Among our domestic animals the sheep has an outstanding virtue; if required to, it can live and produce, at least wool, on the most sparse and inhospitable grazings, and because of this ability it has always tended to be relegated to the less favourable environments for plant and animal growth. On the other hand, as we well know, it can, when given the opportunity, produce at high levels on the highly productive pastures that are a feature of our modern farming.

This versatility of the sheep in general is highly exploited in New Zealand and the position is unique in that we use very few breeds, with the emphasis quite clearly on one, the Romney. It is typical, too, of our sheep farming that an overwhelming proportion of our sheep stocks are dual-purpose animals, and in a system of sheep farming such as this, some sort of balance must be achieved between the demands and outcome of the business of producing meat and wool. It is important, therefore, that we clearly recognise the amount of emphasis that may profitably be devoted to wool-growing as such and that we have some understanding of the principles and processes of wool growth so that we may make full use of feed.

For dual-purpose sheep over the last 10 years, income has had a ratio of about 40 per cent for wool and 60 per cent for meat on specialised fat-lamb farms, and something like 60 per cent for wool and 40 per cent for meat and surplus stock on breeding and store-sheep farms. To add further to this background, wool has some claim to fame in that a good use can be found for it whatever its nature. In general this tends to make quantity of greater importance than excellence, except when premiums may be paid for small quantities of wool with special characteristics.

It is within this framework that we have to examine the woolgrowing enterprise.

\section{Fleece Development and Fibre Growth}

The actual process of growth of the wool fibre is the same in all sheep whatever their breed or nutrition. It is achieved by the transfer in the bloodstream of specific materials derived from food, or from the breakdown of body tissues if the sheep is losing 
weight, to a huge population of wool follicles, each a specialised structure derived from the upper skin and fully squipped with a copious network of blood vessels, a fat gland, and, for some, a sweat gland. The fibre building materials are transferred mainly to the papilla, a pear-shaped body in the base of the follicle.

From the surface of this body there is continuous production of large, rounded cells, and these are pushed up into the follicle shaft as fibre growth proceeds. While this is taking place there is arrangement into the various component layers of the fibre. Some of these rounded cells change into very flat, scale-like cells which form the outer layer of the fibre and others, the majority, change into long, cigar-shaped cells which are cemented together to form the inner and main part of the fibre. Concurrently the contents of the cells condense into tough, fibrous material and about a third of the way up the follicle a process of hardening takes place and the fibre-building process is completed.

A feature of this internal core of cells is that they are of two kinds, unrecognisäble by shape but differing in many ways in their chemical and physical nature. In well-crimped fibres they are arranged as two hemi-cylinders with the most stable fraction always in the inside of the crimp curve and in the more shallow and less well-crimped wools such as the Romney they tend to be arranged with the most stable fraction around the periphery of the fibre. This dual nature of the fibre cortex is the basis of crimp formation which is one of the wool characters visibly affected by feeding level.

The cells that form the fibre arc of similar shape and size in all breeds of sheep irrespective of whether the sheep is producing little or much wool. Clearly then the rate of wool growth will depend on the rate at which these cells are produced and this has been found to depend on the amount of fibre-building material present in the circulating blood.

Some features concerning the population of follicles are particularly important in the relationship between feed and wool growth. The first point is that the total population is very large and varies from about 15 millions on a Border Leicester or Cheviot to up to 50 millions on a very fine Merino. On average, a Romney has some 12,000 per square inch. This huge population takes some considerable time to develop and does so more rapidly and completely through good feeding of the lamb, both before and after birth. In fine-woolled breeds with high potential populations full numbers may not be reached if nutrition is poor; in coarse-woolled breeds with lower potential populations there may be full development of numbers, but the later ones will be weak, and in any period of nutritional stress such as commonly occurs in winter, these weaker members may cease fibre produc- 
tion. A similar sort of effect may be caused by differences in size of follicles and this is firmly associated with the breeding of the animal.

The follicle population develops in a very orderly fashion and is fundamentally founded on the follicle group, which has a typical numerical size characteristic of breed. In some sheep, because of their ancestry, the earlier established follicles of the group may be large and the later members small; if so, conditions of nutritional stress are likely to cause many of the smaller follicles to cease production.

It is important to conceive the idea that the population of units responsible for wool production is very similar to any other biological population. Members vary in number and in individual size and their behaviour depends on relative size and number. There is, too, within this population, all the elements of competition and the typical inability of the weaker members-weak because of nature or nurture-to withstand periods of stress. There is the requirement that sustenance must be continuous for production to occur and there is the characteristic versatility in level of production according to circumstances of supply.

\section{Division of Food M aterials Between W ool Growth and 0 ther Purposes}

There can be no doubt about the complicated nature of the interaction between food supplies and fleece production. Basically the way in which each sheep reacts is an inherited property of the individual, but at the same time there are certain features of wool growth for which all sheep exhibit similar patterns. All of these things can be conveniently discussed as principles, but with the reservation that some of them have been established with penfed animals and with breeds other than the Romney, and hence there cannot be unqualified acceptance that they apply in detail to sheep fed on pasture. There is, however, enough evidence to suggest that these principles can be useful in our circumstances.

Of the total nutrients obtained by the animal from its food, a certain portion is devoted to maintenance, another portion to wool production, and another portion to other productive processes. The actual level of wool production will therefore depend on the way the sheep apportions its feed supply between these three ways of usage and on the level of feed supply in relation to the relative demands of each. For example, the demands for energy and maintenance of a sheep required to travel long distances for its food will be high, and similarly lactation of a breeding ewe will impose a heavy demand on feed materials consumed. This high 
demand also occurs in newly shorn sheep where a high production of heat is called for to maintain body temperature. Nature of feed supplies is of some importance in this process of apportioning. Wool is a very complex protein substance, and wool can be formed only from nitrogenous materials taken in in food. However, these same nitrogenous materials are required for the formation of muscle, for the development of the lamb during pregnancy, and for milk production. They may also be used as a source of energy if the energy-producing portions of the diet, the carbohydrates, are low in quantity. The balance of nutrients in the food is therefore of considerable importance and in general it is the amount of one or other of carbohydrate or protein that sets a practical limit to wool production. On pastures of the ryegrasswhite clover type, protein is usually in ample supply and it is probable that carbohydrate is most often the limiting factor; but on sparse pastures of danthonia and browntop with little or no clover, shortage of protein is likely to be most important.

The most striking example of the different ways in which sheep apportion food materials between wool and other forms of production can be found in a comparison of the Southdown and Merino, which, on a body weight basis, may be expected to have similar food intakes and similar requirements for energy and maintenance purposes. The Merino, however, devotes a great deal of the surplus intake to wool production at the expense of body tissue, to produce three to four times the amount of wool produced by the Southdown, which of course excels in production of body tissue at the expense of wool production.

'With a dual-purpose breed considerable skill must be devoted to maintaining a rational balance between the portions devoted to one or other process. On the other hand, specialised production of meat or wool involves intensification of one or other of these trends.

\section{Wool Growth and the Principle of Diminishing Returns}

At the lowest levels of food intake there is the highest efficiency of conversion of food to wool and the efficiency of utilisation decreases at an ever-increasing rate as food intake is raised to higher levels. The most precise information available regarding this has been obtained using pen-fed animals of Merino and Corriedale breeds and using a particular ration. An interpretation of this information is shown in Table 1, with the proviso that the figures illustrate a principle rather than some finite measure. For example, there is not sufficient information on Romney sheep on pasture to suggest how closely they would conform to these measures. 
TABLE 1-Wool Production in Relation to Level of Food Intake

\begin{tabular}{|c|c|c|c|}
\hline \multirow{2}{*}{$\begin{array}{l}\text { Nitrogen } \\
\text { Intake }\end{array}$} & \multicolumn{3}{|c|}{ Clean Wool Production (units per day) } \\
\hline & Inefficient & Average & Highly Efficient \\
\hline (units per day) & Wool Producer & Wool Producer & Wool Producer \\
\hline 10 & 3.0 & 3.9 & 4.2 \\
\hline $\begin{array}{l}20 \\
30\end{array}$ & 4.2 & 6.8 & $\begin{array}{r}7.8 \\
109\end{array}$ \\
\hline 40 & 4.9 & 10.5 & 13.6 \\
\hline 50 & 4.9 & 11.7 & 15.9 \\
\hline 60 & 5.0 & 12.6 & 17.9 \\
\hline 70 & 5.0 & 13.2 & 19.6 \\
\hline 80 & 5.0 & 13.7 & 21.1 \\
\hline
\end{tabular}

It will be noted that the wool increment per additional unit'of nitrogen consumed decreases as the level of feeding increases, this taking place slowly in the highly efficient sheep and very quickly in the inefficient wool producer. In practice, the low producer is limited by its genetic ability and the high producer by its appetite.

This principle of diminishing returns can be a most useful basis for planning utilisation of food supplies. It does in fact enter into grazing management and always has been and still is the chief guiding principle in any management system designed to promote per acre production as distinct from high production of the individual animal. Calculations indicate that for the average sheep, efficiency of conversion is high until a weight level is reached of approximately $10 \mathrm{lb}$ or $11 \mathrm{lb}$ of greasy fleece, and this would appear to be a reasonable level of production to have as an aim. If animal food can be grown cheaply, as it can in areas of high fertility and kind climate, then the fleece weight aim may be higher and yet still allow a high efficiency of utilisation. The converse applies where provision of a balanced diet in any quantity is costly.

\section{Seasonal Production}

A feature of wool growth that is particularly important in New Zealand concerns differences in month to month production within the year. The pattern is a fundamental one and even though its magnitude may be altered by feeding, its basic nature is evident under all circumstances. Under a system of stock management where an attempt is made to have breeding sheep at a similar weight throughout the year, rate of wool production in January or February will be approximately three times that in June, the month of lowest production. This difference is apparently associated chiefly with the effects that changing day lengths have on the physiological activity of the sheep, and practical means of altering this are difficult to envisage. However, this maximum-minimum ratio of 3 to 1 is vitally important so far as grade of wool is concerned. It is the direct and underlying cause of "break", to the 
extent that this fault can be easily seen in a great proportion of our wool.

The importance of feed supplies at the right time as a means of reducing the worst effects of seasonal production cannot be overstressed. If sheep are held at constant weight in summer and autumn and are fed very well in winter, then the wool growth ratio may be reduced to 2 to 1 and obvious effects of break may not appear. The principle of good winter feeding is well appreciated. However, to produce the maximum modification of the basic seasonal differences this feeding must begin early, because nearminimum rates may be reached in May. Further, it must not be relaxed, because wool growth reacts very quickly to alterations in feed supply and any effect produced is permanently recorded in the staple. In general the assessment of any wool is governed by the part of the staple which grows most vigorously-almost invariably the tip portion-and if even growth is the aim, there must be a corresponding restriction of food in the periods of maximum growth.

While this pattern of wool growth is clearly defined, any approach to modification must be a common-sense one. For example, feed supplies are usually ample in late summer and autumn; the ewe has no other demands at this time and wool growth can be stimulated most easily in this period. There must therefore be some reluctance to forgo these wool-growing advantages, except that excessive fattening in this period should for other reasons be avoided. On the other hand, stimulation of wool growth is most difficult in the May-June-July period, and there might be an equal reluctance to have little return in terms of wool for good feeding in this period, In all this, with our dual-purpose sheep, many other things need to be considered and the principles just discussed should not necessarily override these considerations.

\section{G eneral $E$ ffects of L evel of F eeding}

Largely irrespective of whether the sheep can satisfy a large appetite by being offered a surplus of food or whether it has a large appetite by virtue of its size or inclination, there is in any population of sheep a very close relationship between level of food intake and wool production. It is possible by going to extremes of feeding, both good and bad, to alter wool production by 400 to 500 per cent, and there is a definite tendency for coarserwoolled breeds to respond rather more than fine-woolled breeds to changes in feeding.

Because there is no ready storage, except perhaps as muscle tissue, of materials required for wool growth, there is always a very rapid response in rate of wool growth to change in level of feeding. However, it requires some twelve weeks after a change 
in feeding takes place for wool growth to reach and stabilise at its true level in relation to the new food intake. It can be mentioned here too that depressing effects on wool growth can be equally well induced by any physiological upset that causes even a very temporary interruption in the flow of fibre substrate to follicles, These effects can be quite serious, because they are permanently recorded in the fibre and, if profound, may lead to a number of recognisable faults that are economically important.

A unique feature of wool growth, if compared with other productive processes, is that it continues until food intake is reduced to zero and the animal is not receiving enough to sustain life. For almost all other forms of animal production, usually quite high critical levels of feeding must apply.

\section{Feeding and the Interaction of Fleece Characters}

Apart from copper no substance has been found that when fed or deliberately withheld has a particular and specific effect on wool production. With this exception, level and kind of feeding has a dual and parallel effect on wool growth and other forms of body production, be it growth, fattening, or reproduction. Despite its chemical complexity the wool fibre has a remarkable constancy of composition irrespective of the conditions under which it is grown. The infinite differences that we see in wool are physical differences that are basically the result of the interaction of four things. First is the level of fibre substrate, which depends on quantity of food eaten and the balance of protein and carbohydrate in that food. Second is the number of follicles among which the available fibre substrate has to be divided and this affects fibre volume, which in turn is compounded of the third and fourth factors, length and cross-sectional area of fibre respectively.

For breeds with low density of follicles the number appears to be almost wholly determined by breeding, while in breeds with high density numbers may be modified by early nutrition. From a practical point of view a large number of follicles can be used to produce many small fibres or an equal amount of fibre may be produced by a small number of follicles producing large fibres. There are thus alternative ways of utilising a fixed amount of substrate. However, we are concerned here with effects induced by feeding.

At high levels of feeding leading to above-average wool production, say in the vicinity of a fleece weight 12 to $13 \mathrm{lb}$, practically all follicles are in production and length growth rate is rapid and thickness of fibre is high. A crimp form develops which has particular characters of definition and spacing, both characters being the result of a very complex interaction in which average thickness of fibre, extent of differences in fibre thickness, internal 
arrangement of the fibre, and proximity and interference of other fibres all play a part.

When feeding is reduced to average levels, at which a fleece of approximately $10 \mathrm{lb}$ is produced, there is unlikely to be any reduction in number of active follicles and reduced fibre output is the result of reduction in thickness of fibre and of length growth rate, the latter being the most important. Crimp form will change in the direction of less definition and closer spacing, but these changes will be slight, because probably the only crimp-complex factor that has changed is mean thickness of fibre.

Reduction to levels of feeding that provide only for very low wool production induces some very radical changes in all fleece characters. It nearly always happens that many follicles cease production and the number that do this appears to be greater in sheep that were poorly fed as very young lambs at the time when the fleece was developing. It is also greater in sheep that have what is called a "tippy" or "hairy-tipped" and variable fleece and which were almost certainly rough-coated when they were born. This shedding of fibres is the result of a profound reduction in thickness of fibres due to the low level of wool substrate in the blood as a result of low intake of nutrient. It is a characteristic of all sheep that the minimum productive level of a follicle is reached when the fibre produced is approximately 10 microns $(1 / 2,540$ in.) in diameter (the average Merino fibre is more than twice and the Romney nearly four times this diameter). The end effect of this shedding varies considerably among sheep. In the even-woolled sheep that characteristically has a blocky-tipped staple and a welldefined crimp, all follicles react similarly and if feeding conditions are severe enough then the "quitting" point is reached by the majority of follicles together. When this happens the fleece may strip and this can become a very important source of loss in scrub country. To take the other extreme, in the very variable fleece characterised by large and pointed "hairy-tipped" staples with a very indefinite crimp, the larger follicles in the population are little affected in periods of stress, while the smaller follicles which grow the thinner fibres have, because of the competition effect, to bear almost the whole brunt of lower supply. Many- of these quickly reach "quitting" point. However, they are firmly held in the fleece by the stout, persistently growing fibres and under the influence, chiefly, of alternate wetting and drying, they entangle to form a matt or cott.

Largely due to this differential behaviour and to shedding, crimp form is seriously upset and the fleece loses all semblance of character it might have had.

Apart from these more particular effects of poor feeding, there are other equally important consequences associated with yolk 
and with fleece structure. Good feeding produces a fleece that is bulky and which presents least opportunity for the entry of foreign material and for damage by sunlight and weather, which can be quite profound. In addition more yolk is produced during good feeding and since there is continual migration of this towards the staple tip the maximum protection of fibre is offered. The converse occurs under poor feeding. The fleece is more open and weathering can be severe, particularly on the back. Yolk production is low with consequent less protection of the fleece and an open, weathered fleece permits the entry of much foreign material.

The effects just described can be the result of changes of feeding during the wool-growing year, or they can be the outcome of an accentuation, through feeding, of the normal seasonal changes in rates of wool growth described previously. For New Zealand sheep in general the latter situation appears to be the most common. Either situation is regrettable, since it shows as variation along the length of the staple, in "break", our most frequent fault, in loss of character, and perhaps in cotting. From the point of view of wool excellence a constant rate of wool production, be it high or low, is infinitely preferable to fluctuating rates during the wool-growing year.

From all this it is logical to recommend that where feeding conditions are likely to be poor, the finer-woolled sheep with a more dense and blocky staple are those most likely to produce successfully wool of reasonably good grade. On the other hand the coarser-woolled sheep, which are normally the more variablewoolled sheep, are iikely to incur most of the troubles described above unless they are fed so that they can produce at moderateto-high levels.

\section{Effect of Fleece on Food Intake and Utilisation}

Now to survey briefly the situation in reverse. What is the effect of wool growth on the feed habits or requirements of the sheep? An interesting outcome of some recent work with penned sheep fed a ration of concentrates was that as fleece weight increased the appetite declined by $0.1 \mathrm{lb}$ of concentrate per pound of increase in fleece weight. The reason for this is obscure and at present can be of interest only. However, in these same sheep removal of the fleece led to a very marked temporary increase in appetite lasting for three to four weeks. By inference we might suppose that it is this that is responsible for the usual thriftiness that follows shearing of lambs or backward hoggets.

A most important association of feed supplies and wool, or rather lack of wool, is present after shearing. For the average sheep closely shorn by machines the body heat loss becomes critical at the high temperature of about 85 degrees F. Normally, 
body heat is maintained by heat evolved in the normal process of utilisation of food; however, when extra heat is required, such as that needed to make good extra heat loss through lack of covering or shelter or because of wind, it can come only through utilisation of reserves of fat and protein of the body or from the consumption of more food of a nature that makes it easily digestible and quickly available to the animal. In this respect roughages of the dry, stalky type are, contrary to popular opinion, the least satisfactory. This state of emergency on the part of the animal is considerably less serious when wool has grown to be slightly more than half an inch in length and is insignificant by the time the fleece is about one inch deep. It is clear from work of this nature that the newly shorn sheep should have preferential treatment in the matter of quantity and quality of feed. On the other hand, there can be some doubts about the wisdom of having a very heavy fleece. Argument on this can become very academic and there is little precise information on which to base it. It would seem, however, that it is most likely a disadvantage in that the sheep can become embarrassed by an excess of heat production that it cannot adequately dissipate; it is likely to eat less and what it does eat is used less efficiently.

\section{Summary}

Considering now the whole situation, it becomes clear that apart from copper there is nothing in the way of specific substances in the diet of the grazing animal that causes recognisable or important effects on the structure and nature of the wool fibre without also producing effects on health and other forms of production. The question therefore of feed supplies in relation to wool production largely resolves itself into one of provision of a diet of minerals, carbohydrates, and proteins adequate for the well-being of sheep. We have noted, however, that sheep differ in the proportion that they devote to wool production and, moreover, they differ in the efficiency with which they convert this protein into wool. Some sheep, because of their inherited ability, are very efficient at high levels of production, while others cease to be efficient at low levels, and from the point of view of production per acre it is of use to know that the average sheep becomes relatively inefficient at a level of feeding which is also in excess of that required for efficiency in other productive processes. Wool production per acre therefore demands close attention to stocking rate.

It has been noted, too, that apart from the effect of feeding on quantity of wool there is a complex reaction between level of wool production and the fleece and that fleeces do not behave alike during periods of low wool growth. This is important from the point of view of wool excellence and there is enough evidence to 
suggest that some of the worst effects of poor feeding can be avoided by choice of fleece type. Although the yardstick of productivity should not be based entirely on weight of wool produced, this must take precedence. It is the feature of wool growth most profoundly affected by feeding.

\section{DISCUSSION}

Q. (Williamson): Under intensive fat lamb farming where ewes are on a low plane of nutrition from mid-March to July to enable heavy numbers to be carried, what is the effect on the wool?

A. Fat lamb production and wool production under those conditions are antagonistic. You have to steer a middle course. If ewes are not put on a rising plane of nutrition early enough before lambing, wool deterioration follows. I consider farmers tend to leave the building-up of ewes prior to lambing too late.

Q. (Pemberton): On the graph showing wool production at different times of the year, what type of animal was used?

A. Sheep of all ages averaged. Curve does not change with different type of sheep.

(Pemberton): Quoted example of Merino ewes under very tough conditions where wool quality was not affected and wool weights went up.

A. The Merino is very tolerant to hard conditions due to the constitution of the follicles. The follicular population is even in regard to size. In any variation of feed supply, follicles behave alike. In Romney and coarser breeds, follicle size varies, and under stress some follicles cease producing and result in a fall-off in wool quality. Regarding the question of Merinos giving more wool as well as wool of quality, it is suggested that sheep numbers may have been reduced in the example quoted, and PO feed supply per sheep was improved. The example quoted conflicts with usual experience.

Q. (E. A. Madden): How long does it take for sheep on copper-deficient land to respond when put on to pasture adequate in copper? And how long does it take for sheep going on to copper-deficient soil to show signs of deficiency?

A. The response of copper-deficient sheep when put on to healthy pasture is spectacular. It takes only three or four days for copper to appear above the skin. The reverse process is much slower, as copper is stored in liver, and the time taken for copper deficiency to become apparent depends on the amount of copper stored in the liver.

C. P. Tebb: Farmers shearing twice a year claim they are getting more wool, as well as management advantages. It was his experience that no more wool was obtained.

A. I have no direct experience. In Australia, working with pen feeding, it was found that as the fleece grows, the appetite was depressed. For every $1 \mathrm{lb}$ of wool the sheep put on, they ate $1 / 30$ th less food. Immediately sheep were shorn, their appetite doubled. On this experience, the practice of shearing lambs would appear sound to encourage appetite and consequently growth rate would increase. It is suggested that lambs on rape should be shorn once they have adjusted themselves to the crop after a week or so, and increased appetite and rate of growth should follow. Multiple shearing offers two advantages- 
firstly, the sheep eats more and consequently produces more; and secondly, less wool is lost off the back of the sheep. About $\frac{1}{4} \mathrm{lb}$ extra wool per sheep would be gained by twice a year shearing.

Q. (C. J. Hamblyn): In some high rainfall districts in the North Island, with no great extremes of climate, and where wool damage was a major problem, single shearing in March and April was practised. This gave better fleece quality. Would it also give better yield?

A. From personal experience with harvesting wool in the best possible condition for preservation, the autumn was the best time to shear. The best time to shear varies from place to place, and we should aim at having the wool short in the season of the year when the most rain and the worst weather conditions are experienced. Even within a radius of thirty miles from Lincoln College it is not possible to give a recommendation, on time of shearing, because of the great variation of climate. 